\title{
Could Science be Interestingly Different?
}

\author{
Veli Virmajoki \\ University of Turku \\ vevirm@utu.fi
}

\begin{abstract}
In this paper, I investigate the issue of the contingency and inevitability of science. First, I point out valuable insights from the existing discussion about the issue. I then formulate a general framework, built on the notion of contrastive explanation and counterfactuals, that can be used to approach questions of contingency of science. I argue, with an example from the existing historiography of science, that this framework could be useful to historians of science. Finally, I argue that this framework shows the existing views on historical contingency and counterfactuals in a new light. The framework also shows the value of existing historiography in philosophical debates.
\end{abstract}

\section{Keywords}

historical necessity - history and philosophy of science - contrastive explanation historical counterfactuals - inevitabilism - contingentism

\section{Introduction}

Could science be different? In this paper, I investigate this issue. The debate between inevitabilists and contingentists concerns the question of whether science could be different from what it actually is, or if it is necessary that science has the particular features that it in fact has. Inevitabilists argue that it is inevitable that science has certain features, while contingentists argue that science could have different features from what it in fact has. These are not mutually exclusive positions. Hardly anyone denies that some features of science are contingent (for example, the exact notations used). Yet it is also clear that there are cases where people have differing views on whether or not 
certain features of science could be different from what they actually are. It is here that the debate is of philosophical and historical interest.

By focusing on the contingency of science, I do not mean to suggest that science is fundamentally different or independent from other human practices. Science may or may not be just like any other human activity. However, the nature of science is a question that can be answered only after historical and philosophical study. The issue of the contingency of science is one that can lead us to a better understanding of the relationship between science and other human activities. For this reason, I focus on the contingency of science in this paper. Moreover, one could argue that science is a special kind of activity with respect to contingency. Such views cannot be dismissed without a closer look. For example, scientific realists could argue that scientific activities are limited by the way the world is. ${ }^{1}$ Science tracks the truth about mindindependent reality, and this fact sets very strict limits to the kind of science we can have. ${ }^{2}$ Thus, the realists could argue that science is much more restricted than human activities in general. On the other hand, the argument could be made that science is much less restricted than other human activities since science is an elite culture that does not have to care about politics, economy, and the like. Perhaps both of these views are wrong and science is just as contingent as any other human activity. However, before we can answer questions on the contingency of science, we need some tools to help us approach such questions. The development of those tools is the main task of this paper. Therefore, I focus on the contingency of science more as a methodological choice than as a statement about the special nature of science.

In this paper, I make three main arguments:

1. Science is a multidimensional global enterprise. Because of this, having a different science can mean many things. We must specify what we mean

1 Stathis Psillos, Scientific Realism: How Science Tracks Truth (Routledge, 1999) is an excellent introductory book to scientific realism.

2 The connections between scientific realism and the contingency of science is, of course, a much more complicated issue than suggested here. See: Léna Soler, Emiliano Trizio and Andrew Pickering, Science as It Could Have Been. Discussing the Contingency/Inevitability Problem (University of Pittsburgh Press 2015); Léna Soler, "Revealing the analytical structure and some intrinsic major difficulties of the contingentist/inevitabilist issue," Studies in History and Philosophy of Science Part A 39:2 (2008), 230-241; Howard Sankey, "Scientific realism and the inevitability of science," Studies in History and Philosophy of Science Part A 39:2 (2008), 259-264. 
by different science, and in what way this different science would be an interesting alternative to our actual science.

2. We can approach questions on the contingency of our actual science by using a framework built on the notion of contrastive explanations and counterfactual scenarios in the historiography of science.

3. The framework developed in this paper makes the issue of the contingency of science relevant to a wide range of historians. The framework also helps us see how the existing historiographical studies can be relevant to questions of contingency.

In the next section, I begin my investigation by briefly introducing the existing debate between contingentists and inevitabilists in the philosophy of science (in short: the $C$-I debate). ${ }^{3}$ However, it must be made clear that my task in this paper is not to argue for inevitabilism or contingentism, and that the principal aim of my framework is not to solve the $\mathrm{C}-\mathrm{I}$ debate. The reason I introduce the $\mathrm{C}-\mathrm{I}$ debate is because it has been a source of insight and inspiration for my investigation. From this debate, I have come to understand that

(i) only some alternatives to the existing science would be relevant, and that

(ii) historiographical studies play a fundamental role in answering questions of contingency. The debate is essential to understanding the framework I formulate.

Once we have gathered the most fruitful insights from the $\mathrm{C}-\mathrm{I}$ debate, I then formulate a framework of contrastive explanations and define the concepts of contingency and inevitability within this framework. This framework

(i) connects questions of contingency and inevitability directly to issues that are interesting,

(ii) enables us to pinpoint historical events and processes on which the degree of contingency of a given feature of science depends, and

(iii) tells us what kind of (counterfactual) considerations are relevant in assessing the degree of contingency of a given feature of science.

This framework does not make questions of contingency completely empirically soluble, but it nevertheless helps us find common ground between rival

3 I use the term "C-I debate" to refer to this particular debate. See next section. 
views and clarify where they disagree. Thus, the framework is best understood as a philosophical tool.

Once this framework is in place, I demonstrate its application using Matthew Stanley's study, “An Expedition to Heal the Wounds of War': The 1919 Eclipse and Eddington as Quaker Adventurer." Given the information in Stanley's paper, I ask how the contingency of observations of gravitational deflection can be approached. This example shows how asking contrastive questions enables us to use actual historiographical studies in the discussions on the contingency of science. However, it also shows that many questions remain open-some requiring further historical research, and others philosophical reflection.

In the final sections, I point out how my framework relates to the existing discussions of contingency and counterfactuals in the philosophy of history. I show that there are interesting advantages if these issues are approached in the way suggested in this paper. I also point out why it is important that existing historiographical studies can be used to answer questions of contingencies, and in philosophy in general.

\section{Insights from the $\mathrm{C}-\mathrm{I}$ debate}

Recently, there has been rich debate between inevitabilists and contingentists. In 2008, Studies in History and Philosophy of Science and Isis both devoted a special issue to this topic. In 2015, a book named Science as It Could Have Been: Discussing the Contingency/Inevitability Problem was published and included a variety of articles devoted to the theme. Of course, the debate had its beginnings much earlier, and can be found, for example, in Ian Hacking's frequently cited paper "How inevitable are the results of successful science?"5

The debate is nuanced. Katherina Kinzel's analysis can be used as a helpful guide to the complexities of the debate. ${ }^{6}$ However, the debate usually centers on the features of science that have traditionally been under discussion in philosophy of science, such as theoretical commitments. As Joseph Rouse puts it:

4 Matthew Stanley, "An Expedition to Heal the Wounds of War': The 1919 Eclipse and Eddington as Quaker Adventurer," Isis 94:1 (2003), 57-89.

5 Ian Hacking, "How inevitable are the results of successful science?" Philosophy of Science 67:3 (2000), 58-71.

6 Katherina Kinzel, "State of the field: Are the results of science contingent or inevitable?" Studies in History and Philosophy of Science Part A 52 (2015), 55-56. 
Does the emphasis on ontological commitments suggest that, despite all the talk about scientific practice, we philosophers still believe that the really important changes in science concern theoretical beliefs and ontological commitments? Or is the contingency issue itself a new way to reassert the philosophical primacy of theoretical commitments? ${ }^{7}$

Moreover, the question is usually about the possibility of a science that is fundamentally different from but equally successful as the actual science. Ian Hacking writes:

I asked: How inevitable are the results of successful science? Take any result $\mathrm{R}$, which at present we take to be correct, of any successful science. We ask: If the results of a scientific investigation are correct, would any investigation of roughly the same subject matter, if successful, at least implicitly contain or imply the same results? If so, there is a significant sense in which the results are inevitable. ${ }^{8}$

Along similar lines, Léna Soler defines contingentism and inevitabilism as follows:

\section{Contingentism:}

(I) more or less the same initial conditions obtain as those which have occurred in the history of our own science;

(II) nevertheless, the possibility, as 'final' (subsequent or later) conditions, at least in the long run, of an alternative physics,

(i) as successful and progressive as ours, and

(ii) which yields results irreducibly different from ours (notably which involves an ontology incompatible with ours).

Inevitabilism:

(I) if more or less the same initial conditions obtain as those which have occurred in the history of our own science;

(II) and a successful and progressive physics has indeed been developed;

7 Joseph Rouse, "Laws, Scientific Practice, and the Contingency/Inevitability Question," Science as It Could Have Been (2015), 321.

8 Hacking, "How inevitable are the results of successful science?" 61. 
(III) then, inevitably, as 'final' (subsequent or later) conditions, at least in the long run:

(i) more or less the same results and the same ontology as our own,

(ii) or different but reconcilable results and ontologies as our own. ${ }^{9}$

Soler's definition helps us set aside the overly trivial and speculative definitions of contingentism and inevitabilism. First, we may notice that it is trivially true that if human beings had never existed, there would be no science. It is also true that if human beings were very different from what they are, there would not be any science. For example, it could have been the case that human beings were only interested in drinking beer, and science as we know it would not exist. This case does not fit Soler's definition.

Secondly, it is too easy to be an inevitabilist if one simply claims that in the end only one science will exist, and that no other science is possible. The characterization must specify what is meant by "the end": Is it a situation in which no alternative considerations for the accepted science exist? If so, the debate will begin anew with the question of the possibility of such an end point. Perhaps the end could be seen as a situation where all our possible material needs are satisfied. Then the inevitabilist claim would be that if there came a point where all our possible material needs were satisfied, then there would only be one accepted science, and thus no alternative science could be accepted without diminishing material welfare. This implies that there might be no end point in the development of science, and would thus make the inevitabilist position uninteresting. Thus, as Soler's definition points out, inevitabilists must minimally claim that there actually exist or will exist features of science that cannot be different from what they are, given that certain antecedent conditions hold. The claim cannot be that science has or will have certain necessary features if a certain goal is achieved. Since the C-I debate is so closely connected to the idea of antecedent conditions, the history of science has an essential role to play in the debate. ${ }^{10}$

There are three main insights that I draw from the C-I debate. First, the debate must be about whether some antecedent conditions in history could

9 Soler, "Revealing the analytical structure and some intrinsic major difficulties of the contingentist/inevitabilist issue," 233. (The formulation of the passage is slightly changed.).

10 See: Andrew Pickering, Constructing Quarks: A sociological history of particle physics (University of Chicago Press, 1984); James T. Cushing, Quantum Mechanics: Historical Contingency and the Copenhagen Hegemony (University of Chicago Press, 1994); Peter J. Bowler, Darwin Deleted. Imagining a World without Darwin (The University of Chicago Press, 2013); Soler et al. Science as It Could Have Been; and the papers in Isis 99:3. 
have led to a different science. Secondly, the history of science has an essential role in the debate. Thirdly, a discussion about the contingency of science cannot proceed without an explication of what is meant by different science. In the C-I debate, different science usually means equally successful but fundamentally different science. While this focus on the possibility of equally successful but fundamentally different science is understandable from the perspective of philosophy of science, this is where I leave the C-I debate behind and widen the scope of discussion on contingency in the history of science.

The Point of Departure

We already noted that Joseph Rouse ponders why theoretical commitments have been so central to the $\mathrm{C}-\mathrm{I}$ debate. He also writes:

Grant that the instruments, experimental systems, and models with which scientific understanding is realized are more obviously contingent. It does not follow from the mere recognition that abstract ontological commitments are the only conceivable locus of scientific inevitability that such commitments are all that important. ${ }^{11}$

This seems correct to me, but we can go even further. There is an enormous variety in the topics that historians of science are interested in. Some of them are interested in the relationship between science and religion in the past, others in the history of medical institutions. The list could go on and on. Historians do not only study what the past was like. They are also professionals in building pictures about alternative ways of life. Historians of science are well positioned to spot significant aspects of our current practices and describe interesting alternatives to those practices - alternatives that would mean perhaps drastic changes in our lifestyle. Equal success is neither necessary nor sufficient for something to be an interesting alternative to science. It is not necessary because contexts of historical inquiry exist where an interesting alternative to our present science lacks some features that make our science so successful. Why is our present biology loaded with naturalistic explanations rather than religious ones? It would certainly be an interesting (although, arguably, not as successful) alternative to our present science if biology looked for religious explanations - an alternative that some quarters try to advance. On the other hand, equal success is not sufficient. For example, in a medical context there

11 Rouse, "Laws, Scientific Practice, and the Contingency/ Inevitability Question," 321-322. 
could be a hypothesis that is not an interesting alternative to an accepted one, since it would not suggest changes in the treatment of patients. Even if this alternative hypothesis would have been as successful as the accepted one, this does not guarantee that it is an interestingly different alternative $\mathrm{e}^{12}$ to a historian who is interested in the treatments that are used. Moreover, the contingency of features of science is a matter of degree. Even if everything besides theoretical commitments are obviously contingent, we can still ask how contingent these features are. I now proceed to build a framework that can be used to approach the degrees of contingency of the variety of features that historians of science are interested in.

\section{Counterfactuals, Explanation and Contingency}

In this section, I argue that the best way to approach questions of contingency is to build counterfactual scenarios that would have led to an interestingly different science, and then evaluate the plausibility of these scenarios. In other words, we need to know what should have happened in the past in order for there to be some alternative to actual science, and only then evaluate how plausible or far-fetched that occurrence was. In the following, I develop the details of this approach.

In my earlier work, ${ }^{13}$ I defended the present-centered approach, also known as presentism, in the historiography of science. This approach has the following structure:

1. By rational discussion, we isolate the significant features $(\mathrm{F})$ of the present science.

2. Next, we isolate such features $\mathrm{F}^{*}$ that: if the present science had the feature $\mathrm{F}^{*}$ in contrast to the actual feature $\mathrm{F}$, the present science would be interestingly different from what it actually is.

3. The task of the historiography of science is to provide explanations of the form: had there been (in the past) an event ${ }^{14} \mathrm{Z}$, in contrast to the actual

\footnotetext{
12 See the next section for what is meant by "interesting alternatives."

13 Veli Virmajoki "Miten tieteenhistorian pitäisi valita tutkimuskohteensa?" ["How Should the Historiography of Science Choose its Targets of Study?"] Ajatus 72 (2015).

14 Usually, we must find a set of events that satisfies this condition. I will discuss the limiting case-only one event—-to simplify matters.
} 
event $\mathrm{Y}$, the present science would have the feature $\mathrm{F}^{*}$ instead of $\mathrm{F}^{15}$ In other words, the historiography of science provides explanations for significant features of the present science. ${ }^{16}$

Using this approach, we can define the contingentist position as follows:

It could have been the case that science has the feature $\mathrm{F}^{*}$ rather than the actual feature $\mathrm{F}$, where the difference between $\mathrm{F}$ and $\mathrm{F}^{*}$ is considered interesting in the given context of discussion.

We can accept that $\mathrm{F}^{*}$ could have been the case if and only if (a) someone points out a counterfactual past event $\mathrm{Z}$ that would have led to $\mathrm{F}^{*}$, and (b) it is shown that the occurrence of $\mathrm{Z}$ in the past is not an impossible (or extremely far-fetched) scenario. ${ }^{17}$

Moreover, the contingency of a certain feature F of science is a matter of degree:

Feature F can be judged to be (a) inevitable if and only if the occurrence of any $\mathrm{Zi}$ is seen as impossible and (b) a truly chancy feature if $\mathrm{Z}$ is a part of the actual history. Moreover, the more far-fetched the occurrence of $\mathrm{Z}$ is judged to be, the more inevitable feature $\mathrm{F}$ is.

For example, if it turns out that a theory that is actually held was chosen from among many theories by a flip of a coin, then the fact that we hold that particular theory instead of another is a chancy feature of science. On the other hand, the fact that we have theories of celestial motion lies at the other end of the continuum of contingency. Only in the far-fetched scenarios where human beings were not interested in repeating patterns of time (the understanding of which is necessary for agriculture) there would be a complete lack of theories of celestial motion. Finally, if there are many counterfactual scenarios such

15 There has been much discussion about contrastive explanations. See: B. van Fraassen, The Scientific Image (Oxford University Press 1980); P. Lipton, “Contrastive Explanations," In Knowles (ed.), Explanation and its Limits (Cambridge University Press 1990) 247-266. In this formulation, I mainly follow James Woodward's theory from Making Things Happen (Oxford University Press, 2003).

16 This is a normative view on the historiography of science. The suggestion is that the historiography of science should, and sometimes does, provide such explanations. Moreover, much of existing historiography of science can be fruitfully read through such a conception of historiography of science. It is a philosophical view that goes beneath the surface of what historians actually say.

The example in the next section suggests how this can be done. 
that each of these scenarios would have led to $\mathrm{F}^{*}$, then the contingency of $\mathrm{F}$ depends on the scenario which is judged to be the most plausible one.

The claim that a feature $\mathrm{F}$ of the present science is contingent can (and must) be substantiated by (a) showing that the existence of the feature $\mathrm{F}^{*}$ would have made the present science interestingly different, by (b) pointing out event $\mathrm{Z}$ that would have led to $\mathrm{F}^{*}$, and by (c) making sophisticated judgments about the plausibility or the far-fetchedness of the occurrence of $\mathrm{Z}$ (i.e. about the scenario where $\mathrm{Z}$ is the case). In this way, the framework here helps us understand how the degrees of contingency can be approached by using historical studies, as we will see in the next section.

The definition above requires that, in order to get discussions going, judgments about the plausibility of historical scenarios involving $\mathrm{Z}$ can be made and that it can be assessed that $\mathrm{Z}$ would have led to $\mathrm{F}^{*}$. Nothing general about this topic can be said within the limits of this paper. However, in the next section, I give an example of how historical study can be used to argue for certain degrees of contingency of certain features of science. This discussion points out that, even in the absence of a theory of how judgements about the plausibility of counterfactual scenarios work, historians always make these kinds of judgments when explaining historical processes. Moreover, these judgments make sense and can be rationally debated. Of course, there might not exist a point where everyone agrees on a given set of counterfactuals. ${ }^{18}$ Nevertheless, we will see that the framework developed here can narrow down the topics of disagreement and highlight which disagreements are relevant with respect to a given topic. Moreover, there exists a comforting amount of analysis of the use of counterfactuals in history, ${ }^{19}$ and there exist, in the literature concerning the $\mathrm{C}-\mathrm{I}$ debate, many studies that speak to the possibility of finding out points of history that have had an influence on the path that has led to the present situation in science. ${ }^{20}$

18 Moreover, if someone is not skeptical only about particular evaluations of historical counterfactuals but denies the possibility of historical counterfactual altogether, questions on contingency of science are not meaningful to this person. After all, descriptions of science "as it could have been" are descriptions of counterfactual science. Thus, global skepticism towards counterfactuals is not something that affects my framework alone.

19 On the use of counterfactuals in history, see: Alexander Maar, "Possible uses of counterfactual thought experiments in history," Principia: An International Journal of Epistemology 18:1 (2014), 87-113. Tim De Mey and Erik Weber, "Explanation and Thought Experiments in History," History and Theory 42:1 (2003), 28-38. Johannes Bulhof, "What if? Modality and history," History and Theory 38:2 (1999), 145-168 and Journal of the Philosophy of History $10(3)$.

20 See footnote 10. 
Before proceeding to the example, one thing needs to be taken into consideration. The isolation of significant features is typically carried out in the following manner: we take features that are prima facie significant and then attempt to establish more general principles that make these features significant. In a continuous process, we then compare the features and the principles in such a way that the judgments about the significance of some feature and the plausibility of our principles can both be adjusted. For example, we may say that the observation of gravitational deflection (see details below) is a significant feature of science since it plays an important part in the acceptance of relativistic physics (and thus in the overall shape of our physics) and in the understanding and technology that it provides. If these were different, we would have an interestingly different science. Arguably, the way we see the world and the technology we use impact our lives in a remarkable way. Now, if one accepts this, a sociologist might point out that, since the technological state of our society is one of the features that makes science significant, gender distribution in science is also a significant feature of science since it shapes the distribution and use of technology in a way that matters. If the distribution of technological resources were different, we would live in an interestingly different world. In contrast, if we used different symbols in the periodic table, science would not be interestingly different. Everything we know about chemistry and the applications of this knowledge would be the same. At least one could, if they disagreed, argue for the significance of the symbols themselves.

In this way, we can rationally evaluate which features of science are significant. ${ }^{21}$ Once we know the significant features and why they are significant, we also know which alternatives to these are the interesting ones. What would be an interesting alternative to science depends on what we want from science, and what achievements of science (good or bad) we see as relevant. Ultimately, considerations such as these are based on our values. Deep questions of values cannot be discussed here. However, we have seen that it is possible to distinguish the interesting alternatives to science from the non-interesting ones.

21 Jean-Marc Lévy-Leblond nicely illustrates the wide variety of features that might be taken to be significant: "Had the alternate approach been realized [in physics], there would be a number of significant differences: [among other things] pedagogical approaches to the theory would be different and certainly more convincing [and] the large cultural impact of relativity theory would have been quite different, from its many and often problematic philosophical exegeses [...] to its vernacular manifestations, for instance in popular iconography (Einstein's tongue!)." (“On the Plurality of (Theoretical) Worlds," Science as It Could Have Been, 341-342.). 


\section{5 Eddington and the Gravitational Deflection}

In "An Expedition to Heal the Wounds of War': The 1919 Eclipse and Eddington as Quaker Adventurer," (2003), Matthew Stanley describes the process that led to Eddington's 1919 eclipse expedition and the observation of gravitational deflection. According to Stanley, the execution of this expedition was a pivotal event that had a notable effect on scientists' acceptance of Einstein's general theory of relativity.

I use Stanley's article to demonstrate the framework formulated above. The main goal of this section is to show that the framework can help us use historical studies to evaluate the degrees of contingency of particular features of science. I show that while we can have progress in these evaluations, we cannot settle the questions once and for all. I will make it explicit when further historical research can settle an open question and when we are forced to use considerations that are more philosophical — and thus also potentially undecidable - in their nature.

Two things must be noted: first, for the sake of illustration, I assume that Stanley's account is correct. I also make, to the same end, some claims that might seem controversial with the purpose of isolating interesting issues that are connected to contingency and inevitability. This illustration does not have the purpose of arguing for or against inevitabilism. It only aims to show how the issue can be approached by using existing historical research and how such research can fuel the discussion.

Stanley highlights the following aspects of the process leading to the expedition:

The eclipse's scientific significance had gradually become clear over the course of the war years. The first mention of relativity's prediction of the bending of light in the Observatory was an anonymous 1913 note entitled "Gravitation and Light."22

[Eddington published] Report on the Relativity Theory of Gravitation, a small volume that was the first complete treatment of general relativity in English. Soon, enough interest in the theory had been generated to begin investigation into the logistics of an expedition to test it. ${ }^{23}[\mathrm{M}]$ any astronomers thought the expedition would be a waste of time. The refugee scientist, Jonckheere, warned that there were several different

\footnotetext{
22 Stanley, "An Expedition to Heal the Wounds of War': The 1919 Eclipse and Eddington as Quaker Adventurer," 71.

23 Ibid.
}

JOURNAL OF THE PHILOSOPHY OF HISTORY (2018) 1-22 
mechanisms that might duplicate the predicted deflection, making observations useless. [Yet] such a vague objection, Lindemann said, should carry little weight compared to Einstein's detailed and consistent theory. ${ }^{24}$

[Astronomer Royal] Frank Dyson felt that while the theory was speculative, its implications were so important that it needed to be investigated. ${ }^{25}$

Einstein's theory predicted that a ray of light traveling near a massive object, such as the sun, would undergo a small but measurable deflection of its path. This was one of the three "classic" relativistic effects predicted by Einstein: the advance of the perihelion of Mercury was already established, and the measurement of the redshift of the solar spectrum was proving difficult. This left observing the gravitational deflection as the only realistic hope of confirming general relativity. ${ }^{26}$

Passages such as these convey the impression that the British scientific community was interested in making the observations purely for scientific reasonseven the objections to the journey were based on scientific considerations. The expedition to an eclipse was thought to be the only way to test the theory, and there were scientific reasons to think that the expedition could bring useful results. Yet Stanley points out that "[d]iscussions such as these were important in the scientific debate but had little impact on the actual planning of the expedition. This was chiefly in the hands of two astronomers who were also interested in ramifications beyond the scientific test: Eddington and Dyson." ${ }^{27}$ The execution of the expedition required the individual effort of Eddington and Dyson despite the fact that the Joint Permanent Eclipse Committee, a group set up by both the Royal Society and the Royal Astronomical Society to pool the intellectual and logistical resources of the two groups, already existed.

The question we must ask is why Eddington was so keen on the expedition. Stanley points to Eddington's Quaker background and the context of the First World War. Stanley describes how the beginning of the war changed the attitude of British society, including scientists, toward the Germans. Despite an early declaration that science is above politics, the reality of war resulted in hatred toward the Germans, as Stanley points out in detail. ${ }^{28}$ In this context,

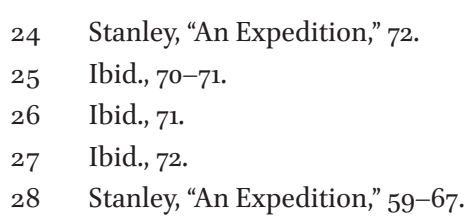


it was Eddington's Quaker background that shaped his attitude toward the situation:

Eddington's reaction [...] was largely shaped by his membership in British society's traditional bastion of pacifism: the Society of Friends. ${ }^{29}$

The Friends' goal was to demonstrate "the brotherhood of man overstepping all artificial barriers of race, politics or creed, which we believe to be the only true foundation upon which the family of nations can rest." 30

Those Friends who ventured to Europe to relieve this suffering, both during and after the war, worked in difficult and sometimes dangerous conditions. These relief workers came to be known as "adventurers," and they hold a special place in Quaker history as men and women who journeyed into far and foreign lands as a duty of conscience. The strategies used by these adventurers became the models for Eddington's efforts to use the eclipse expedition as a tool in repairing international relationships. ${ }^{31}$

Given Stanley's arguments, we can ask to what degree the observation of gravitational deflection was a contingent matter. To use the framework formulated in the previous section, we must begin by defining the significant feature of science that resulted from Eddington's expedition. Arguably, the answer is: the significant feature $\mathrm{F}$ in this case is that the observation of gravitational deflection has been made. A significant alternative $\left(\mathrm{F}^{*}\right)$ to this feature $\mathrm{F}$ is that the observation has not been made.

Next we must ask the question (C):

What conditions should have been different so that the observation would not have been made?

We can begin our search for the answer by formulating the following question and answer in order to find these conditions:

Q1. Why did Eddington execute the expedition rather than not?

E1. Because Eddington attempted to reunite the international scientific community due to his Quaker background and because the expedition had the chance to produce scientifically interesting results due to the interest in Einstein's theory.

29 Ibid., 61.

$30 \quad$ Ibid., 68.

31 Ibid., 67-68. 
One might think that Eddington's execution of the expedition of 1919 is the condition that can be given as an answer to the question $\mathrm{C}$, and thus answering the question Q1 provides the details of the answer. If this is the case, then $\mathrm{F}$ is a rather contingent feature of science: it depends on Eddington's personal religious worldview, and it is easy to provide plausible scenarios in which Eddington did not have this worldview-he could have lost his faith in humanity because of the war. However, the details given by E1 are not the answer to C. This is due to the fact that Q1 leaves it open as to whether or not someone else would have made the expedition if Eddington had not. Thus, we must continue our search for the answer to $\mathrm{C}$.

Next we can ask:

Q2.Why didEddington, rather than someone else, execute the expedition?

E2. Because Eddington was concerned about the unity of the international scientific community and wanted to unify it due to his Quaker background, and no one else had this concern. ${ }^{32}$

It might be argued that once we know why Eddington, rather than someone else, executed the expedition, we can then evaluate how plausible it is that the expedition would have been executed without Eddington. But the contrast in Q2 is misleading if this was the evaluation we wanted. E2 tells us in which situation someone else would have executed the expedition instead of Eddington, but Q2 assumes that the expedition would have been carried out in either case. E2 in itself would become interesting only if an argument was given for the claim that the identity of the executor of the expedition had an impact on the making of the observations. The possibility of this must be settled by investigating whether or not Eddington had a unique set of skills that were necessary in making the observations. This is a step in the right direction, but we must still continue our search for the answer to $\mathrm{C}$.

We can ask:

Q3. Why was the observation attempted ${ }^{33}$ in 1919 rather than later?

E3. Because Eddington was concerned about unifying the international community and had the urge to work at a quick pace in this matter due

32 Stanley's description makes one think that Eddington played the pivotal role due to his unique concern in the context.

33 This innocent change of terms is due the fact that later an expedition itself may not have been necessary (it could have perhaps been made in a place where an observatory already existed, etc.). 
to his Quaker background (and because of lucky occurrences during the journey).

This is again a step in the right direction, because E3, unlike E1 and E2, specifies the conditions in which the expedition (and thus the observations) would not have been made in 1919. It can be argued that the execution of the expedition in 1919 was a rather contingent event based on, again, the contingency of Eddington's background. But once we notice that we defined the significant feature $\mathrm{F}$ to be that the observation of gravitational deflection has been made, and once we notice that almost one hundred years have passed since 1919, we see that the contrast in $\mathrm{Q}_{3}$ is not relevant to answering question $\mathrm{C}$. This is due to the fact that the answer to Q3 says nothing about the years since 1919 and thus E3 does not tell us anything about how plausible it is that the observation would have been sought later in the twentieth or at the beginning of the twenty-first century. ${ }^{34}$ The correct question to ask is :

\section{Q4. Why was the observation attempted rather than not?}

E4. Because there was an increasing scientific interest in Einstein's theory and because the observation of gravitational deflection was viewed as a practical way to test the theory.

We saw earlier how Stanley points to these factors. British scientists were planning the expedition even before Eddington and Dyson took the execution into their hands. Moreover, Stanley does not refer to or give any reason to believe that had Eddington not become involved when he did, the observation of deflection would not have been made at any point in history. This means that what seemed to make the feature F highly contingent, i.e. Eddington's religious worldview, is no longer a condition that can be used to answer question $\mathrm{C}$.

34 If we had formulated $\mathrm{F}$ in our illustration in another way, for example, saying that it is significant that the observation was made in 1919 and not later, then a highly contingent condition-Eddington's Quaker background - would be the condition on which the significant feature depends. F could be defined in this way if we wanted to know, for example, the degree of contingency of a certain other feature $G$, that has become part of science only recently and that is a result of developments that began in 1919 when Eddington made the observation of gravitational deflection. That science has the feature $G$, and not some alternative to it, would be judged to be highly contingent if it was necessary, in order to have $\mathrm{G}$, that the expedition took place in 1919. The more recent the features of science in which we are interested, the more likely it is that they could have been otherwise. 
We can now explicate the philosophical lessons that can be drawn from the example. First, it must be noted that we did not analyze the contingency of having the observation of gravitational deflection in detail. The example only pointed out how it is possible to find the conditions on which having the significant feature $\mathrm{F}$ instead of $\mathrm{F}^{*}$ depends. We came to the conclusion (for the sake of illustration, of course) in $\mathrm{Q}_{4}-\mathrm{E}_{4}$ that only if there had been no scientific interest in Einstein's theory, it could have been possible that the gravitational deflection would never have been observed. To evaluate the contingency of having the observation of gravitational deflection requires an investigation that evaluates the plausibility of scenarios in which there was no interest in Einstein's theory. How plausible is the scenario where Einstein's theory was not formulated? How plausible is the scenario where Einstein's theory was ignored by the scientific community?

These questions cannot be answered based on Stanley's paper. It is possible to get closer to the right answer through further historical studies. These studies could investigate the following questions:

1. How widespread was the idea of spacetime curvature among scientific communities?

2. How was the evidential value of such observations viewed in scientific communities?

3. How seriously did scientists plan to isolate German scientists, including Einstein, after the war?

4. What was the status of physics among the socio-political environment? Were the politicians planning to solely focus on the aspects of physics that would have direct impact on military technology?

Of course, no matter how much empirical information we have, questions of counterfactual paths of science cannot be unequivocally answered. Here we come to the point where different philosophical considerations and intuitions about science divide us on the issue of contingency. Can we, for example, assume that the world has a determined structure? Is science an opportunistic field where very small changes in the social environment can direct scientists to pursue different activities? Do observations really matter in theory choice? This means that there is no guarantee that discussions on the contingency of a particular feature of science can be settled.

However, once we have identified crucial historical points on which our actual science presumably depends, we have also limited the number of philosophical considerations that are relevant to settling the questions of contingency. For example, if we are able to show that the existence of Einstein's 
theory (and the scientific community's interest in the theory) is the best candidate for the factor on which observations of gravitational deflection depend, then the considerations of the connections between observations and theoretical works play a role in the attempts to decide the contingency of those observations. On the other hand, if empirical research leads us to believe that Eddington's religious background is the best candidate for the factor on which the observation of gravitational deflection depends, then the considerations of the connections between personal background and scientific work play a role in the attempts to decide the contingency of those observations. Thus, the framework formulated in the last section does not rid us of all disagreement in questions of contingency, but does help narrow down the relevant considerations in a particular case. Thereby, the framework helps us find common ground between rival views.

There is one more lesson to be learned from the example. It must be noted that the difference between having the observation of gravitational deflection and not having that observation is interesting only in certain contexts of discussion, as the definition of contingency given in the previous section asserts. An example of this kind of context would be a discussion on the building of GPS navigation devices. One could wonder how these devices became so useful, and someone could answer the question by pointing out that this is partly due to the fact that we have begun to understand the effects of gravitational deflection. If the observation of deflection had not been made, we might still have inaccuracies in these devices and they would not be as useful as they are. We would attempt to find the cause of the malfunction of the devices in places it does not exist. Thus, it is significant that our thinking is no longer limited by assumptions based on a Euclidean view of space. In this way, it becomes clear that there exists a hidden structure in our definition of significant feature $\mathrm{F}$ that is given by the context of discussion: $\mathrm{F}$ is that the observation of gravitational deflection has been incorporated into our thinking and $\mathrm{F}^{*}$, the significant alternative, is that we do not use the concept of gravitational deflection in our thinking in the problem situation which we face in the modern world.

The last point is important since it counters the following argument:

Every feature of science is dependent on a previous event, and this event is again based on some previous event, and so on. Moreover, even if we ignore all the trivial factors that present science depends on (such as the existence of humankind), every event in the given chain is a contingent event and these contingencies add up to a highly contingent present situation. For example, the observation of gravitational deflection was dependent on the formulation of Einstein's theory; the formulation of 
Einstein's theory was dependent on the physics of the nineteenth century; the physics of the nineteenth century was dependent on the work of Newton; and so on. The chain could have broken at any point, and thus it is a great coincidence that we have observed gravitational deflection.

First, it must be noted that this kind of thinking is flawed. Causal chains in the world do not work in this neat manner. There are situations of overdetermination, pre-emption, non-transitive causal chains and overlapping causal chains that make this kind of argumentation simply naïve. ${ }^{35}$

Secondly, and more substantially, this argument can be overcome by simply pointing out that if Newtonian mechanics, for example, had never developed, then there would not be a theoretical framework against which the consequences of not having evidence for gravitational deflection could arise. If we had not dealt with the actual questions of physics, then the thinking process that uses knowledge of gravitational deflection would not exist, nor would the thinking processes that take the absence of gravitational deflection as a serious possibility (a process like this would be the futile search for the causes of the malfunctioning of GPS navigation devices). In the absence of physics, lacking one piece of data would be the least of our concerns. To summarize, the counterfactual situations in which an alternative feature $\mathrm{F}^{*}$ is assumed to be part of science must be somewhat close to our actual situation. Otherwise the differences between the features of our actual science and the interesting alternatives to these would not be meaningful. As Rouse puts it: "Differing judgments about scientific significance thus matter well beyond whether they lead to differences in accepted truth claims. We need to ask which accepted beliefs matter to science, and how they matter."36

To ask whether science could have been different is to ask whether or not it could have been different in an interesting way. Asking whether science could have been different in an interesting way is not the same thing as asking whether science today could have been fundamentally different or missing altogether. Only historical studies that show the degree of contingency of the

35 James Woodward's Making Things Happen is a good place to become familiar with these issues and the complexity of causal thinking and philosophy of causation. An example (not from Woodward): My soccer team's losing to ManU depends on the goal they scored in the first minute. This depends on my team's inability to stop the attack. However, had we been able to stop the attack earlier, ManU would still have scored a goal in the second minute (by understanding our defense better) and my team would have lost anyway.

36 Rouse, "Laws, Scientific Practice, and the Contingency/Inevitability Question," 320. 
things that we find significant in science can increase our reflective understanding of this question.

\section{Contingency, Counterfactuals and the Relevance of Historiography}

\section{Historical Contingency: The Nature of Relevant Initial Conditions}

The concepts of contingency and necessity are widely discussed in the philosophy of history. One definition closely similar to the one presented in this paper is that of Yemima Ben-Menahem. According to Ben-Menahem, "contingency (necessity) varies in magnitude: the greater (smaller) the sensitivity to initial conditions, the greater the degree of contingency (necessity)." ${ }^{37}$ To reiterate:

Contingency: Similar causes lead to different types of effects. High sensitivity to initial conditions.

Necessity: Different types of causes lead to similar effects. Low sensitivity to initial conditions. ${ }^{38}$

However, there are remarkable differences between the definition of this paper and the definition of Ben-Menahem. First, my definition of contingency does not require that similar causes lead to different outcomes. ${ }^{39}$ The factor $\mathrm{Z}$ that would have led to $\mathrm{F}^{*}$ does not need to be similar to $\mathrm{Y}$ in order for there to be contingency. All that is needed is that $\mathrm{Z}$ is not far-fetched. ${ }^{40}$ Secondly, even if different types of causes lead to similar effects, this does not mean that science is inevitable. In my framework, this similarity of effects can still mean that there are some interesting differences between them, and thus there can exist contingency. Similarly, even if the effects are very different, this does not automatically mean that one is an interesting alternative to the other. A great advantage of my framework is that it makes explicit what differences and similarities we are interested in. We do not need to find out the general properties of the causal structures in history to gain knowledge of the contingency of

37 Yemima Ben-Menahem, “Historical contingency," Ratio 10:2 (1997), 102.

38 Ibid., 101.

39 Notice that also Soler's definition (section 2) mentions more or less the same initial conditions.

40 There does not seem to be any reason to equate similarity and non-far-fetchedness. Pulling the trigger of a gun and merely holding a finger on the trigger are very similar events. Yet the pulling of the trigger can be a far-fetched alternative in a situation where an experienced and trustworthy police officer holds their finger on the trigger. 
features we are interested in. We can focus on the structures and features we are interested in.

\section{Reconsidering Counterfactual History}

It is important to make note of how the contrastive explanations based on counterfactuals differ from what is known as study of counterfactual histories. In these studies, an event $\mathrm{C}$ is assumed to be the cause of an event $\mathrm{E}$ and the question one tries to answer is: What would have happened had $\mathrm{C}$ not occurred, ${ }^{41}$ or more generally, what could have happened had certain things been different in the past? On the other hand, the formulation of a contrastive explanation begins by specifying the relevant alternatives to the event $\mathrm{E}$ and proceeds to find out which alternatives $\left(\mathrm{C}^{*}\right)$ of $\mathrm{C}$ would have led to some relevant alternative $\left(\mathrm{E}^{*}\right)$ to $\mathrm{E}$. Although studies of counterfactual histories can achieve the conclusion that science would be interestingly different had certain things been different, this is not guaranteed. The reasoning could also lead to the conclusion that science would be different, but not interestingly so, or to the conclusion that science would not be different.

This means that my framework offers an energy-efficient way of approaching questions of contingency. When we first specify what differences we are interested in and then proceed backwards in history to the causes of these differences (rather than forwards, as in the study of counterfactual history), we are able to bypass a variety of considerations that do not have direct relevance to understanding the contingency of science in particular cases.

\section{The Value of Existing Historiography in a Philosophical Debate}

The C-I debate has produced and highlighted many excellent historical studies that are relevant to the issue of contingency. ${ }^{42}$ The debate has shown that good historical work is extremely useful in approaching the issue of the contingency of science. Nevertheless, once we are interested in generalizing the questions on the contingency of science to a vast range of issues that historians of science are interested in, a general framework that tells us how we can approach questions of contingency needs to be in place. There are two reasons for this. First, historians of science have produced high quality works. It is advantageous to have a framework that can be used to extract relevant points from these works; there is no need to wait for studies that directly intend to discuss the degree of contingency of a particular feature of science. Secondly, the framework can work as a tool in the historical research that discusses such questions. Due to

\footnotetext{
41 Maar, "Possible uses of counterfactual thought experiments in history," 88.

42 See examples in footnote 10.
} 
its complete generality, it can unify the structures of such studies. We also saw above that my framework is energy efficient. Moreover, since historical case studies in the philosophy of science face difficult methodological issues, ${ }^{43}$ the possibility of using historical studies that are made independently of the issue of contingency is an advantage. ${ }^{44}$

\section{$7 \quad$ Conclusion}

In this paper, I formulated a framework that helps us discuss the degree of contingency of any feature of science that a historian of science might be interested in. While this framework does not give a perfect algorithm to solve questions of contingency, it nevertheless tells us what types of questions to ask and what to consider when approaching questions of contingency. The framework also shows the place of our evaluations of significance in questions of contingency. Some alternatives to science are more interesting than others, and we should focus on those interesting alternatives. Furthermore, the framework shows how already existing historical studies can provide insights into questions of contingency. Although the framework is a very general one, it is humble in one important sense: we can only approach the contingency of science in a piecemeal manner, asking whether this or that particular feature of science could be interestingly different.

43 See Katherina Kinzel, "Narrative and evidence. How can case studies from the history of science support claims in the philosophy of science?" Studies in History and Philosophy of Science Part A 49 (2015), 48-57; and Joseph C. Pitt, "The Dilemma of Case Studies: Toward a Heraclitian Philosophy of Science," Perspectives on Science 9:4, 373-382.

44 Of course, there does not exist a perfectly objective historical study, and historical research can benefit from the discussions on contingency and inevitability, as Soler argues in "Introduction. The Contingentist/Inevitabilist Debate: Current State of Play, Paradigmatic Forms of Problems and Arguments, Connections to More Familiar Philosophical Themes," Science as It Could Have Been, 22-23, and as is argued in this paper. However, it is still useful to be able to use historical studies that are made independently of the debate. They are probably the most objective ground that we may wish to have. 